DOI: 10.12731/2227-930X-2017-4-53-68

УДК 004, 37.02

\title{
СПРАВОЧНАЯ ПРАВОВАЯ СИСТЕМА «КОНСУЛЬТАНТПЛЮС» КАК ИНСТРУМЕНТ РЕАЛИЗАЦИИ МЕЖДИСЦИПЛИНАРНЫХ СВЯЗЕЙ В ВУЗЕ
}

\section{Хамер Г.В., Корнеева Р.В.}

Стандарты выстего образования предусматривают освоение студентами комплексных универсальных, общепрофессиональных и профессиональных компетенций на основе междисциплинарных связей. Как показывает практика, в обучении различных дисциилин эффективно применение справочной правовой системь (СПС) «КонсультантПлюс». Освоение возможностей СПС является важной составляющей подготовки будущего специалиста, начинается с первых курсов обучения в рамках базовых дисциилин и должно использоваться в дальнейшем в течение всего срока обучения для нормативно-правового обеспечения различных дисииплин специиализации.

Цель-разработка и последующее внедрение в учебный процесс СПС «КонсультантПлюс» в качестве эффективного инструмента реализации связей между дисциилинами.

Метод или методология проведения работы: использовались интерактивные методы обучения, а также статистические методы анализа результативности исследования.

Результаты: повышение качества изучения СПС «КонсультантПлюс», приобретение опыта в решении актуальных практических задач, эффективный контроль знаний студентов.

Область применения результатов: разработанную технологию изучения СПС «КонсультантПлюс» иелесообразно применять в вузовском обучении при изучении различных дисциплин: правовых, дисциилин информационных технологий, статистических, 
дисциплин специальности, чтобы происходило эффективное освоение необходимых будущим специилистам компетенций.

Ключевые слова: справочная правовая система «КонстультантПлюс»; межсисциилинарные связи; компетентностный подход.

\section{REFERENCE LEGAL SYSTEM "CONSULTANTPLUS" AS A TOOL FOR IMPLEMENTING INTERDISCIPLINARY CONNECTIONS IN HIGH SCHOOL}

\section{Hamer G.V., Korneeva R.V.}

The standards for higher education provide for the development of students a comprehensive, universal, General and professional competencies through interdisciplinary connections. As practice shows, in the teaching of various disciplines, effective use of reference legal systems (RLS) "ConsultantPlus". Development opportunities RLS is an important component of training future specialists. It starts with the first courses of study in basic disciplines and should be used in the future during the period of training for regulatory support of various disciplines of specialization.

\section{Purpose}

Development and subsequent introduction in the educational process RLS "ConsultantPlus" as an effective tool for the realization of connections between disciplines.

Methodology: used interactive teaching methods, and statistical methods of analysis of the impact of research.

Results: improving the quality of study RLS "ConsultantPlus", gain experience in solving actual practical problems, effective monitoring of students ' knowledge.

Practical implications: developed by the technology study RLS "ConsultantPlus" should be used in University education in the study of various disciplines: legal, disciplines of information technology, statistical, special subjects to the effective development necessary to the future experts skills. 
Keywords: reference legal system "ConsultantPlus"; interdisciplinary communication; competence approach.

\section{Введение}

Внедряемые Федеральные государственные образовательные стандарты высшего образования предусматривают сквозное освоение студентами комплексных компетенций на основе междисциплинарных связей [1-8]. Перспективным представляется использовать справочную правовую систему «КонсультантПлюс» для реализации принципа междисдиплинарных связей [9-11].

Освоение возможностей СПС «КонсультантПлюс» начинается с первых курсов обучения в рамках базовых дисциплин. Проблема на этом этапе заключается в том, что компания «КонсультантПлюс» предлагает сборник примеров для освоения системы, который ориентирован в основном на специалистов с профессиональной подготовкой и не позволяет эффективно использовать при обучении первокурсников [12]. Другой существенной проблемой является необходимость использования СПС в течение всего срока обучения студентов и трудностями ее применения из-за существующей изолированности изучения дисциплин.

Полагаем, что решить указанные проблемы можно путем разработки банка заданий, который позволит применять СПС «Консультант Плюс» как инструмент реализации междисциплинарных связей и формирования комплексных компетенций, предусмотренных стандартом высшего образования.

\section{Цель и задачи}

Целью исследования является повышение качества реализации образовательных программ в соответствии с требованиями ФГОС высшего образования путем совершенствования механизма междисциплинарных связей. Для достижения цели полагаем необходимым решение следующих задач: исследовать тематику и создать банк заданий для освоения возможностей СПС на начальных курсах; разработать банк профильных заданий с учетом 
связей базовых и дисциплин специализации; разработать банк междисциплинарных заданий для взаимосвязанных дисциплин; проанализировать эффективность применения в учебном процессе разработанных заданий.

\section{Материалы и методы}

Поставленные задачи реализовывались поэтапно. На первом этапе были разработаны задания, демонстрирующие целесообразность использования СПС «КонсультантПлюс». Проведены бинарные занятия студентов, уже владеющих СПС и первокурсников, для демонстрации целесообразности использования СПС и формирования мотивации ее изучения.

На втором этапе был проведен анализ имеющегося сборника примеров, разработанного сотрудниками СПС»КонсультантПлюс». Проведенный анализ показал, что на занятиях со студентами начальных курсов нашей академии используется лишь небольшая часть (15\%) предлагаемых заданий. Это связано, с тем, что он ориентирован, в основном, на обучение широкого круга специалистов, уже имеющих профессиональную подготовку, а не первокурсников.

Для решения данной проблемы нами был разработан банк заданий общей тематики, рассчитанный на начальный уровень подготовки студентов. Для этого сначала было проведено исследование тем для разработки новых заданий. Чтобы создаваемый сборник примеров учитывал тематический интерес студентов-первокурсников, был проведен конкурс правовых вопросов в специально созданной группе в контакте. В результате проведенного конкурса были выявлены интересные и актуальные для студентов темы: права и обязанности, образование и трудоустройство, социальные гарантии, жилищные проблемы и другие. На основании отобранных вопросов был разработан банк заданий для освоения возможностей СПС «КонсультантПлюс» для студентов начальных курсов.

Компетентностный подход в обучении предполагает, что студенты должны развивать сформированные компетенции при изучении СПС «КонсультантПлюс» в рамках базовых курсов, используя СПС 
при изучении профильных дисциплин, т.е. в течение всего срока обучения в вузе. Поэтому на третьем этапе, во-первых, было проведено исследование связей базовых дисциплин и дисциплин специализации; во-вторых, разработан банк профильных заданий.

На практике формирование междисциплинарных связей возможно на основе сотрудничества и общения преподавателей профильных и базовых дисциплин. Это позволит обеспечить закрепление навыков работы с СПС «КонсультантПлюс», понять прикладное назначение СПС, лучше понимать и усваивать текущий материал изучаемой дисциплины.

Максимальная потребность студентов в использовании СПС «КонсультантПлюс» возникает, как правило, на старших курсах при изучении взаимосвязанных дисциплин специализации. Поэтому на четвертом этапе было, во-первых, проведено изучение междисциплинарных связей дисциплин специализации; во-вторых, разработана система междисциплинарных заданий и методических рекомендаций по их использованию; в-третьих, проверена эффективность применения СПС.

Изучение междисциплинарных связей позволило выделить следующий модуль дисциплин для студентов специальности «Таможенное дело», где применение СПС «КонсультантПлюс» в обучении эффективно (рис. 1, 2).

Созданный банк заданий содержит задания трех видов: задания общей тематики, профильные и междисциплинарные задания. Задания общей тематики разработаны с пошаговыми вариантами решения в СПС «КонсультантПлюс», что позволяет их использовать при самостоятельной внеаудиторной работе студентов [13]. Такие задания способствуют формированию у студентов требуемых универсальных и общепрофессиональных компетенций. Профильные задания предлагаются в виде кейс-заданий, требующих анализа и применения СПС. Решение таких задач позволит параллельно с изучением основной дисциплины получить навыки практического применения СПС, что способствует развитию уже имеющихся компетенций. Междисциплинарные задания для взаимосвязанных дисциплин 
специализации представляют собой комплексные задания прикладного характера. Такие задания представляют ситуационные кейсы, для решения которых необходимы знания нескольких взаимосвязанных дисциплин и умение применять СПС «КонсультантПлюс».

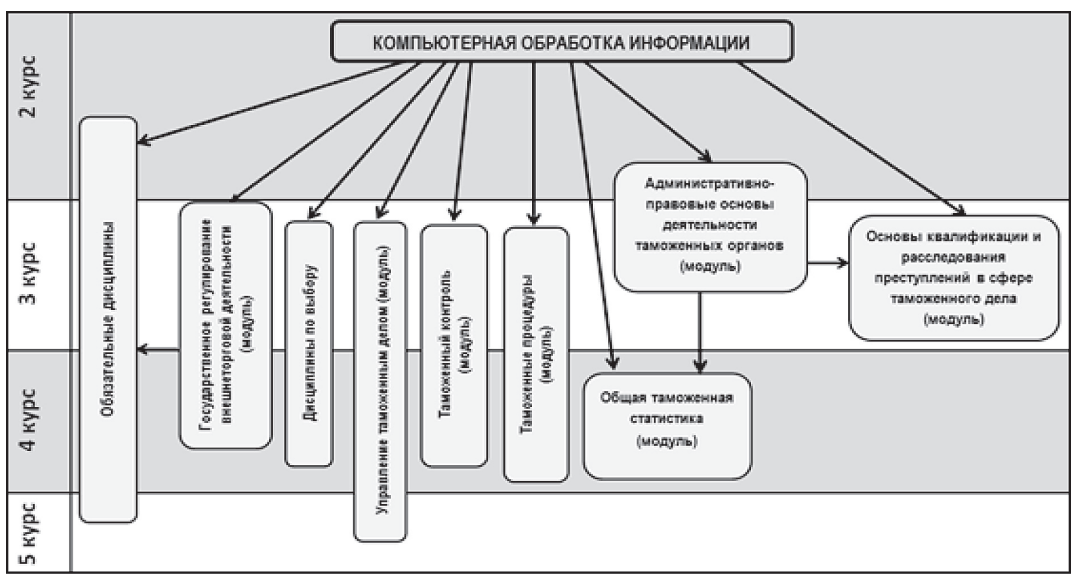

Рис. 1. Схема применения междисциплинарных связей на основе

СПС «Консультант Плюс» при подготовке специалиста таможенного дела

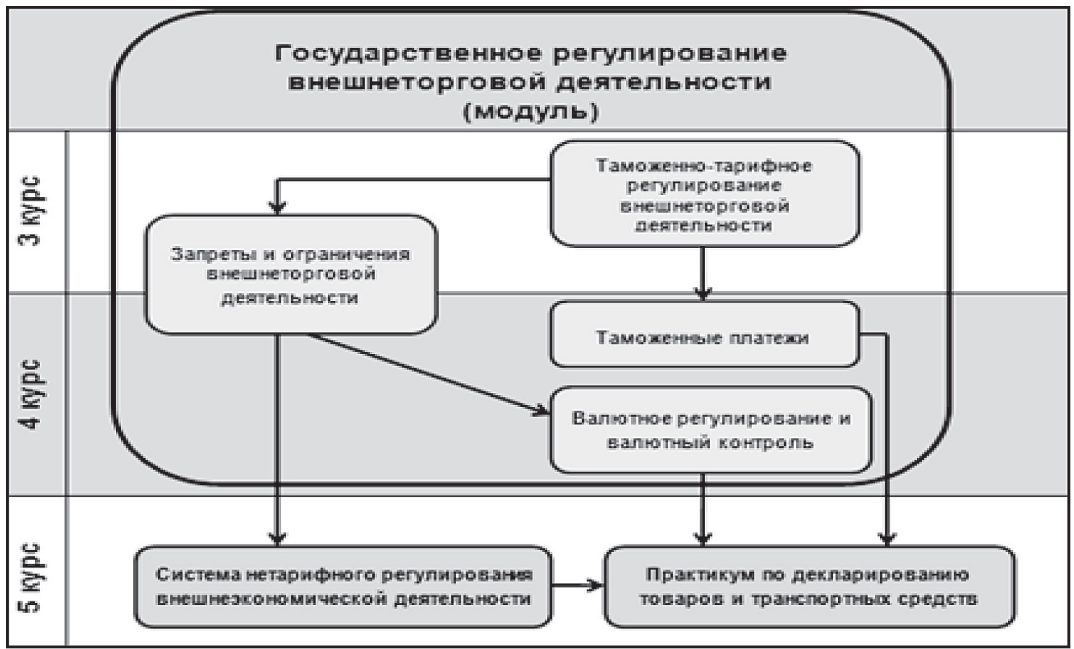

Рис. 2. Схема применения междисциплинарных связей при изучении модуля «Государственное регулирование внешнеторговой деятельности» 
Кроме применения СПС «КонсультантПлюс» в учебном процессе, самостоятельной внеаудиторной работе студентов рекомендуется использовать тренинго-тестирующую систему СПС «КонсультантПлюс» в режиме тестирования. Предварительно студентам предлагается использовать её в режиме самоконтроля, что следует дополнительно учитывать в балльно-рейтинговой системе [14].

Составленный банк заданий можно использовать не только в процессе обучения, но и для организации конкурсных мероприятий в рамках каждой выпускающей кафедры, например, в рамках Недели науки, которая ежегодно проводится в нашей академии, проведение конкурсов «На лучшего знатока Таможенного законодательства», «На лучшего пользователя СПС «КонсультантПлюс», online-игры «Покупатель всегда прав?!», другие мероприятия [15-20].

\section{Результаты}

Результативность исследования проверялась количественными и качественными измерителями (рис. 3).

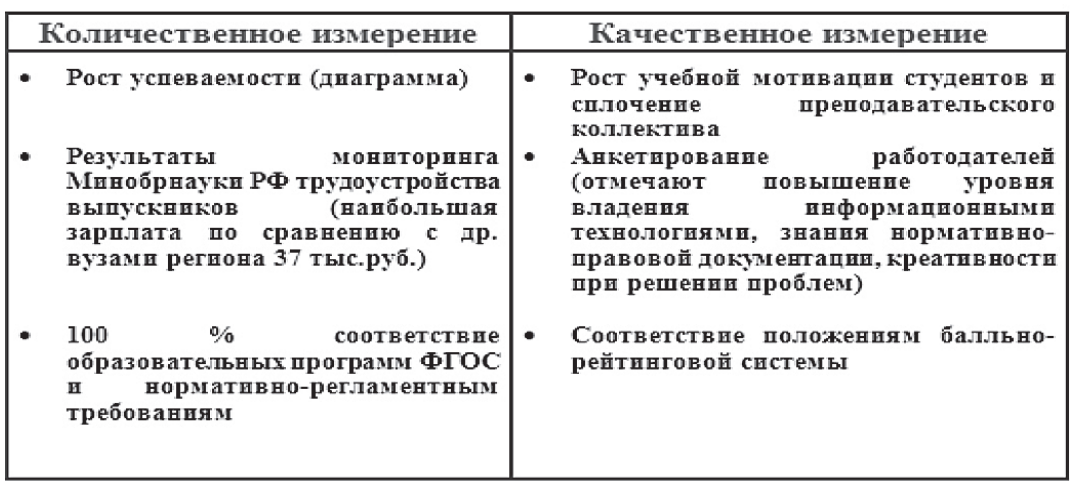

Рис. 3. Количественные и качественные индикаторы результативности исследования

Для проверки результативности проводимого исследования использовались 2 группы студентов, поступивших на 1 курс дневного отделения по специальности «Таможенное дело». Из этих групп мы отобрали по 15 студентов с одинаковыми баллами оце- 
нок по 3 дисциплинам (по результатам сдачи ЕГЭ): русский язык, математика, обществознание. Уже на первом курсе обучение этих студентов велось различным образом: в 1 группе (А) с использованием СПС «КонсультантПлюс» по всем правовым и многим др. дисциплинам, а во 2 группе (В) -без применения СПС.

В течение 5 лет обучения студентов фиксировали результаты сдачи ими тех дисциплин, в которых использовалось обучение с применением СПС «КонсультантПлюс». Результаты сдачи сессий студентами отражены на диаграмме (рис. 4).

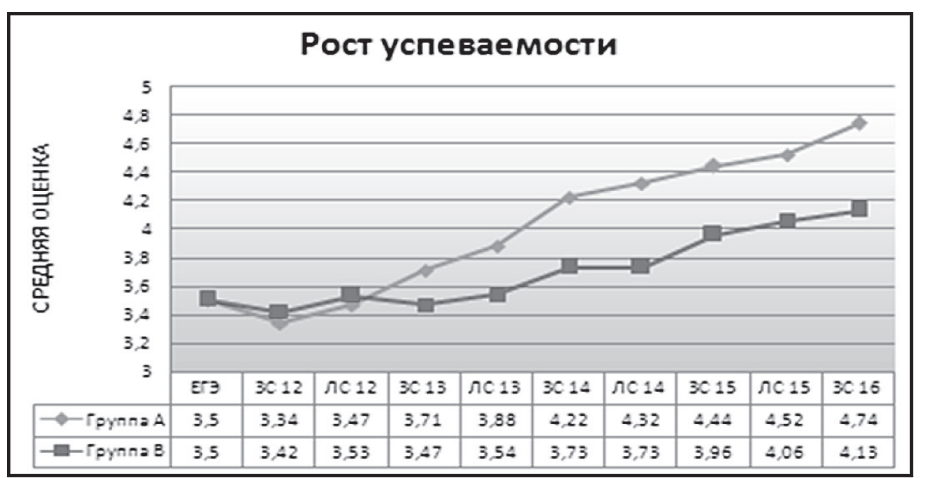

Рис. 4. Диаграмма успеваемости студентов групп А (с применением СПС «КонсультантПлюс») и В (без использования СПС «КонсультантПлюс»)

Средняя успеваемость студентов группы А (с применением СПС «КонсультантПлюс») выросла на 35,4\%, а в группе В (без использования СПС «КонсультантПлюс») - на 18,0\%.

Итоги проведенного исследования показали, что выросла учебная мотивация студентов: они с интересом осваивают СПС «КонсультантПлюс» и многие становятся сертифицированными пользователями. Если раныше студенты получали сертификаты просто пользователей, то начиная с 2016 года многие получили сертификаты профессионалов.

Традицией стали различные конкурсы, которые проводит Центр СПС «КонсультантПлюс», постоянными участниками которых являются преподаватели и студенты академии. В одном из таких конкур- 
сов «Даем старт профессионалам» в номинации «Лучший куратор» Калужский филиал стал победителем в 2016 и 2017 годах. Количество студентов, участвующих в конкурсах и играх растет с каждым годом.

\section{Выводы}

Оптимальное применение СПС «КонсультантПлюс» в реализации междисциплинарных связей обеспечивает сквозное освоение предусмотренных стандартом высшего образования компетенций в течение всего срока обучения в вузе, а результатом прохождения образовательной программы является специалист, обладающий комплексным пониманием задач, возникающих в сфере его профессиональной деятельности, и знанием инструментов, применяемых для их решения.

\section{Перспективы развития}

Во-первых, динамика изменений Российского законодательства требует поддержания созданного банка заданий в актуальном состоянии. Во-вторых, постоянно меняющиеся интересы и запросы студентов требуют изучения тем правовых и профильных вопросов для решения в СПС. В-третьих, сама справочная правовая система постоянно развивается, появляется масса новых технических возможностей, а значит необходимость обновлять банк заданий. В-четвертых, расширяется перечень дисциплин, изучаемых с использованием СПС «КонсультантПлюс» [21-22].

\section{Список литературы}

1. Самылов П.В. Развитие профессиональных компетенций и интерактивная образовательная технология // Человеческий капитал. 2012. №9 (45). С. 94-99.

2. Самылов П.В. Формирование общекультурных и профессиональных компетенций студентов вуза в условиях проектно-деятельностного обучения // Человеческий капитал. 2012. №1 (37). С. 94-96.

3. Хропов Е.С., Селиверстова С.Ю. Роль общекультурных и общепрофессиональных компетенций в формировании базовой модели 
гуманитарной подготовки студентов экономико-управленческого профиля // Мир науки, культуры, образования. 2015. №1(50). C. 203-207.

4. Самылов П.В., Хомутова О.Ю. Компетентностный подход и интерактивные образовательные технологии в подготовке менеджеров // Материалы научно-методической конференции Северо-Западного института управления. 2009. №1. С. 25-35.

5. Хамер Г.В. Формирование, оценка и развитие компетенций будущих управленцев в процессе изучения цикла математических и естественнонаучных дисциплин / Хамер Г.В., Смирнов В.Ю., Корнеева Р.В. // В мире научных открытий. 2014. №5.1 (53). С. 462-474.

6. Самылов П.В. Проектирование карьерных траекторий через развитие профессиональных компетенций муниципальных служащих // Вестник Российского университета дружбы народов. Серия: Государственное и муниципальной управление. 2014. №4. С. 65-72.

7. Belousova A.I., Pavlov D. A. Study of problems of organization of knowledge in the field of information technology // International Journal of Advanced Studies (IJAS). 2013. Vol. 3. No 4, pp. 13-17. DOI: 10.12731/2227-930X-2013-4-3.

8. Самылов П.В. Проектно-деятельностное обучение в образовательном процессе вуза // Человеческий капитал. 2012. №1 (37). C. $92-94$.

9. Программа информационной поддержки российской науки и образования. Сайт «КонсультантПлюс - студенту и преподавателю». https://www.consultant.ru/edu/highschool/vuz/programm/ (обращение 18.10.2017).

10. Чепцов А.С. Технологии СПС «КонсультантПлюс» в научной и учебной деятельности студентов и преподавателей // http://econf. rae.ru/pdf/2009/11/1ecfb46347.pdf

11. Корнеева Р.В. Методы и перспективы развития использования СПС «КонсультантПлюс» в учебном процессе // Новые технологии в образовании: Сборник статей III Международной научно-практической конференции. ООО «Научно-инновационный центр. 2015. С. 230-233. 
12. CD. КонсультантПлюс: Высшая Школа. - Выпуски 20-22.

13. Хомутова О.Ю. Внеаудиторная работа студентов как важный элемент формирования компетенций будущего управленца // Государственное управление. Электронный вестник. 2010. №25. С. 9.

14. Мезенцева А.С. К вопросу использования компьютерных систем тестирования знаний // В сб.: Наука, образование, общество: тенденции и перспективы развития. Сборник материалов III Международной научно-практической конференции: в 2-х томах. Главный редактор О.Н. Широков. 2016. С. 191-192.

15. Хамер Г.В. Сайт и квест «Интерактивное путешествие по местам боевой славы Калуги» как средства воспитания патриотизма подрастающего поколения / Асеев П.С., Хамер Г.В. // Вестник Калужского филиала РАНХиГС. Калуга, 2015. С. 6-8.

16. Анохина Л.В. Творческие задания как средство развития креативных способностей в учебном процессе // Материалы научно-методической конференции Северо-Западного института управления. 2009. №1. С. 81-88.

17. Тютин Д.В., Гомалеев А.О. Организация управления практикой студентов профессиональной образовательной организации на основе процессного подхода // Калужский экономический вестник. 2017. №1. С. 61-66.

18.Хропов Е.С. Подготовка будущих учителей дисциплин гуманитарного цикла к использованию информационных технологий для развития творческих способностей учащихся // В сб.: Социокультурные проблемы подготовки современного педагога: Материалы Международной научно-практической конференции. 2008. С. 286-288.

19. Самылов П.В. Пути решения методологических проблем проектного обучения: опыт Калужского филиала РАНХиГС // Известия Балтийской государственной академии рыбопромыслового флота: психолого-педагогические науки. 2014. №3(29). С. 88-95.

20. Самылов П.В. Методологические проблемы проектной деятельности студентов в образовательном процессе // Ценности и смыслы. 2014. №6 (34). С. 106-110. 
21.Никитина О.А. Формирование правовой культуры студентов в процессе изучения иностранного языка: дис. ... канд. пед. наук. Рязань, 2006. 153 с.

22. Довгань В.В. Создание и использование электронного образовательного ресурса в составе информационно-методического обеспечения учебного процесса: дис. ... канд. пед. наук: 13.00.02. М., 2012. 139 c.

\section{References}

1. Samylov P.V. Razvitie professional'nykh kompetentsiy i interaktivnaya obrazovatel'naya tekhnologiya [The development of competencies and interactive educational technology]. Chelovecheskiy kapital. 2012. No 9 (45), pp. 94-99.

2. Samylov P.V. Formirovanie obshchekul'turnykh i professional'nykh kompetentsiy studentov vuza $\mathrm{v}$ usloviyakh proektno-deyatel'nostnogo obucheniya [The formation of common cultural and professional competences of students in terms of project and activity learning]. Chelovecheskiy kapital. 2012. No 1 (37), pp. 94-96.

3. Khropov E.S., Seliverstova S.Yu. Rol' obshchekul'turnykh i obshchepro-fessional'nykh kompetentsiy $\mathrm{v}$ formirovanii bazovoy modeli gumanitarnoy podgotovki studentov ekonomiko-upravlencheskogo profilya [The role of common cultural and General professional competencies in the formation of the basic model of humanitarian training of students of economic-administrative profile]. Mir nauki, kultury, obrazovaniya. 2015. No 1(50), pp. 203-207.

4. Samylov P.V., Khomutova O.Yu. Kompetentnostnyy podkhod i interak-tivnye obrazovatel'nye tekhnologii v podgotovke menedzherov [Competence-based approach and interactive technology in the training of managers]. Materialy nauchno-metodicheskoy konferentsii Severo-Zapadnogo instituta upravleniya [Materials of the scientific-methodical conference of the North-Western Institute of Management]. 2009. No 1, pp. 25-35.

5. Khamer G.V., Smirnov V.Yu., Korneeva R.V. Formirovanie, otsenka i razvitie kompetentsiy budushchikh upravlentsev $\mathrm{v}$ protsesse izucheniya tsikla matematicheskikh i estestvennonauchnykh distsiplin [Formation, 
evaluation and development of competencies of future managers in the process of studying the cycle of mathematical and natural Sciences]. $V$ mire nauchnykh otkrytiy [Siberian Journal of Life Sciences and Agriculture]. 2014. No 5.1 (53), pp. 462-474.

6. Samylov P.V. Proektirovanie kar'ernykh traektoriy cherez razvitie professional'nykh kompetentsiy munitsipal'nykh sluzhashchikh [Designing career trajectories through the development of professional competencies of municipal employees]. Vestnik Rossiyskogo universiteta druzhby narodov. Seriya: Gosudarstvennoe i munitsipal 'noy upravlenie. 2014. No 4, pp. 65-72.

7. Belousova A.I., Pavlov D.A. Study of problems of organization of knowl-edge in the field of information technology. International Journal of Advanced Stud-ies (IJAS). 2013. Vol. 3. No 4, pp. 13-17. DOI: 10.12731/2227-930X-2013-4-3.

8. Samylov P.V. Proektno-deyatel'nostnoe obuchenie v obrazovatel'nom protsesse vuza [Project-action learning in the educational process of the University]. Chelovecheskiy kapital. 2012. No 1 (37), pp. 92-94.

9. Programma informatsionnoy podderzhki rossiyskoy nauki i obrazo-vaniya. Sayt «Konsul'tantPlyus - studentu i prepodavatelyu» [The program of information support of Russian science and education. The website "Consultant - student and teacher"]. https://www.consultant. ru/edu/highschool/vuz/programm/

10. Cheptsov A.S. Tekhnologii SPS «Konsul'tantPlyus»v nauchnoy $i$ ucheb-noy deyatel'nosti studentov i prepodavateley [Technology RLS "ConsultantPlus" in scientific and educational activities of students and teachers]. http://econf.rae.ru/pdf/2009/11/1ecfb46347.pdf

11. Korneeva R.V. Metody i perspektivy razvitiya ispol'zovaniya SPS «Konsul'tantPlyus» v uchebnom protsesse [Methods and prospects of development of the use of RLS "ConsultantPlus" in the educational process]. Novye tekhnologii v obrazovanii: Sbornik statey III Mezhdunarodnoy nauchno-prakticheskoy konferentsii [New technologies in education: Collection of articles of the III International Scientific and Practical Conference]. OOO «Nauchno-innovatsionnyy tsentr. 2015, pp. 230-233. 
12. SD. Konsul tantPlyus [CD. ConsultantPlus]. Vysshaya Shkola. No 20-22.

13. Khomutova O.Yu. Vneauditornaya rabota studentov kak vazhnyy element formirovaniya kompetentsiy budushchego upravlentsa [Extracurricular work of students as an important element of formation of competences of the future Manager]. Gosudarstvennoe upravlenie. Elektronnyy vestnik. 2010. No 25. P. 9.

14. Mezentseva A.S. K voprosu ispol'zovaniya komp'yuternykh sistem tes-tirovaniya znaniy [By the use of the computer systems of testing of knowledge]. $V$ sb.: Nauka, obrazovanie, obshchestvo: tendentsii i perspektivy razvitiya. Sbornik materialov III Mezhdunarodnoy nauchno-prakticheskoy konferentsii [Collection of materials of the III International Scientific and Practical Conference]. Ed. O.N. Shirokov. 2016, pp. 191-192.

15. Khamer G.V. Sayt i kvest «Interaktivnoe puteshestvie po mestam boevoy slavy Kalugi» kak sredstva vospitaniya patriotizma podrastayushchego pokoleniya [The website and the quest "an Interactive journey to places of military glory of Kaluga" as a means of Patriotic education of the younger generation]. Vestnik Kaluzhskogo filiala RANKhiGS. Kaluga, 2015, pp. 6-8.

16. Anokhina L.V. Tvorcheskie zadaniya kak sredstvo razvitiya kreativnykh sposobnostey v uchebnom protsesse [Creative tasks as means of development of creative abilities in the educational process]. Materialy nauchno-metodicheskoy konfe-rentsii Severo-Zapadnogo instituta upravleniya [Proceedings of the scientific-methodical conference of the North-West Institute of Management]. 2009. No 1, pp. 81-88.

17. Tyutin D.V., Gomaleev A.O. Organizatsiya upravleniya praktikoy stu-dentov professional'noy obrazovatel'noy organizatsii na osnove protsessnogo podkhoda [The organization management practices of students of professional educational organizations on the basis of the process approach]. Kaluzhskiy ekonomicheskiy vestnik. 2017. No 1, pp. 61-66.

18. Khropov E.S. Podgotovka budushchikh uchiteley distsiplin gumanitarnogo tsikla $\mathrm{k}$ ispol'zovaniyu informatsionnykh tekhnologiy dlya razvitiya tvorcheskikh sposobnostey uchashchikhsya [Training of future teachers of humanitarian disciplines to the use of information technol- 
ogy for development of creative abilities of students]. Sotsiokul turnye problemy podgotovki so-vremennogo pedagoga: Materialy Mezhdunarodnoy nauchno-prakticheskoy konferentsii [Sociocultural problems of training a modern teacher: Materials of the International Scientific and Practical Conference]. 2008, pp. 286-288.

19. Samylov P.V. Puti resheniya metodologicheskikh problem proektnogo obucheniya: opyt Kaluzhskogo filiala RANKhiGS [Solutions of methodological problems of project learning: the experience of the Kaluga branch of Ranepa]. Izvestiya Baltiyskoy gosudarstvennoy akademii rybopromyslovogo flota: psikhologo-pedagogicheskie nauki. 2014. No 3(29), pp. 88-95.

20. Samylov P.V. Metodologicheskie problemy proektnoy deyatel'nosti studentov v obrazovatel'nom protsesse [Methodological problems of project work of students in the educational process]. Tsennosti $i$ smysly. 2014. No 6 (34), pp. 106-110.

21. Nikitina O.A. Formirovanie pravovoy kul 'tury studentov v protses-se izucheniya inostrannogo yazyka [Formation of legal culture of students in the process of learning a foreign language]. Ryazan', 2006. $153 \mathrm{p}$.

22. Dovgan' V.V. Sozdanie i ispol'zovanie elektronnogo obrazovatel'nogo resursa $v$ sostave informatsionno-metodicheskogo obespecheniya uchebnogo protsessa [Creating and using electronic educational resources in the information-methodical support of educational process]. 13.00.02. Moscow, 2012. 139 p.

\section{ДАННЫЕ ОБ АВТОРАХ}

Хамер Галина Викторовна, заведующая кафедрой естественнонаучных и математических дисциплин, кандидат педагогических наук, доцент

Калужский филиал Российской академии народного хозяйства и государственной службы при Президенте Российской Федерации

ул. Окружная, 4, корп. 3, г. Калуга, Калужская область, 248021, Российская Федерачия

ghamer@mail.ru 
Корнеева Рита Викторовна, старший преподаватель кафедры естественнонаучных и математических дисциплин Калужский филиал Российской академии народного хозяйства и государственной службы при Президенте Российской Федераиии

ул. Окружная, 4, корп. 3, г. Калуга, Калужская область, 248021, Российская Федераиия

r.korneewa@yandex.ru

\section{DATA ABOUT THE AUTHORS}

Hamer Galina Viktorovna, Head of the Department of Natural-Science and Mathematical Disciplines, Candidate of Pedagogical Sciences, Associate Professor

Kaluga branch of Russian Presidential Academy of National Economy and Public Administration

4/3, Okruzhnaya Str., Kaluga, Kaluga Region, 248021, Russian Federation

ghamer@mail.ru

SPIN-code: 4632-0505

Korneeva Rita Viktorovna, senior teache of the department of natural-science and mathematical disciplines

Kaluga branch of Russian Presidential Academy of National Economy and Public Administration

4/3, Okruzhnaya Str., Kaluga, Kaluga Region, 248021, Russian Federation

r.korneewa@yandex.ru 